\title{
An evaluation of portion size estimation aids: precision, ease of use and likelihood of future use
}

\author{
Gemma P Faulkner ${ }^{1}{ }^{2}$, M Barbara E Livingstone ${ }^{1}$, L Kirsty Pourshahidi ${ }^{1}$, \\ Michelle Spence ${ }^{3}$, Moira Dean ${ }^{3}$, Sinead O'Brien ${ }^{4}$, Eileen R Gibney ${ }^{4}$, Julie MW Wallace ${ }^{1}$, \\ Tracy A McCaffrey ${ }^{1,5}$ and Maeve A Kerr ${ }^{1, *}$ \\ ${ }^{1}$ Northern Ireland Centre for Food and Health (NICHE), School of Biomedical Sciences, University of Ulster, \\ Coleraine Campus, Cromore Road, Coleraine BT52 1SA, UK: ${ }^{2}$ Life and Health Sciences, School of Science, IT Sligo, \\ Sligo, Republic of Ireland: ${ }^{3}$ School of Biological Sciences, Queen's University Belfast, Belfast, UK: ${ }^{4}$ Institute of Food \\ and Health, University College Dublin, Belfield, Dublin, Republic of Ireland: ${ }^{5}$ Department of Nutrition and Dietetics, \\ Monash University, Notting Hill, VIC, Australia
}

Submitted 20 April 2015: Final revision received 19 November 2015: Accepted 18 December 2015: First published online 9 February 2016

\begin{abstract}
Objective: The present study aimed to evaluate the precision, ease of use and likelihood of future use of portion size estimation aids (PSEA).

Design: A range of PSEA were used to estimate the serving sizes of a range of commonly eaten foods and rated for ease of use and likelihood of future usage. Setting: For each food, participants selected their preferred PSEA from a range of options including: quantities and measures; reference objects; measuring; and indicators on food packets. These PSEA were used to serve out various foods (e.g. liquid, amorphous, and composite dishes). Ease of use and likelihood of future use were noted. The foods were weighed to determine the precision of each PSEA. Subjects: Males and females aged 18-64 years ( $n$ 120).

Results: The quantities and measures were the most precise PSEA (lowest range of weights for estimated portion sizes). However, participants preferred household measures (e.g. $200 \mathrm{ml}$ disposable cup) - deemed easy to use (median rating of 5), likely to use again in future (all scored either 4 or 5 on a scale from $1=$ 'not very likely' to $5=$ 'very likely to use again') and precise (narrow range of weights for estimated portion sizes). The majority indicated they would most likely use the PSEA preparing a meal (94\%), particularly dinner (86\%) in the home (89\%; all $P<0.001)$ for amorphous grain foods.

Conclusions: Household measures may be precise, easy to use and acceptable aids for estimating the appropriate portion size of amorphous grain foods.
\end{abstract}

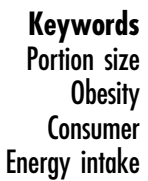

Keywords

Obesity

Energy intake
The wider availability of larger portion sizes (PS) outside the home has contributed to consumers' distorted perceptions of appropriate $\mathrm{PS}^{(1)}$, leading them to overestimate their PS in the home ${ }^{(2)}$. PS management is often considered irrelevant by consumers on a personal level and is deemed necessary only for those on a special diet (e.g. for weight loss) ${ }^{(3-6)}$. Some of the key challenges for consumers with regard to PS management include irregular eating patterns, food serving size (SS; or pack sizes), poor nutrition knowledge, avoiding food waste, lack of cooking skills and availability of leftovers. There is also the tendency to consume larger PS when eating outside the home ${ }^{(5)}$. However, recent research found that almost half of consumers in the UK find it most difficult to achieve appropriate PS when preparing and eating foods in the home ${ }^{(7)}$. Furthermore, consumers generally distrust the SS on food labels as they believe the food industry manipulates them in order to make the nutrient levels seem more favourable ${ }^{(8)}$. Consumers often buy in excess of the SS stated on the food labels as they perceive them to be insufficient ${ }^{(5)}$.

A major obstacle in providing consumer education on appropriate PS is the current absence of national quantitative dietary guidance in the UK. Consumers receive conflicting messages from various sources with different objectives (e.g. weight loss $v$. weight maintenance advice). Changes in dietary messages over time have also contributed to consumer confusion; for example, study participants questioned whether the recommendation for milk was a pint or a glass of milk per day ${ }^{(9)}$. The 'Eatwell Plate' advises on the proportion (but not the specific amount or SS) of each food group to consume ${ }^{(10)}$. 
Therefore, health professionals have called for the introduction of national SS guidance as consumers are confused about what constitutes an appropriate PS for many foods ${ }^{(3,9-12)}$. On the other hand, in the Republic of Ireland, the national dietary guidelines include information on SS for different age, gender and activity levels. However, measuring specific weights and volumes tends to be laborious and time consuming ${ }^{(12)}$ while traditional SS guidance such as 'small, medium or large' may be too ambiguous for consumers ${ }^{(12,13)}$. As a result, the Irish dietary guidelines have recently incorporated more convenient and approximate tools to aid PS estimation (i.e. household measures and reference objects including a $200 \mathrm{ml}$ plastic cup, a teaspoon, the palm of the hand and a matchbox $)^{(14)}$. However, no evaluation of the efficacy, likely uptake or practical application of these aids has been conducted to date. Research elsewhere that has assessed the usefulness of other aids such as food photographs for PS estimation has found equivocal results $^{(12,15-17)}$. Furthermore, the accuracy (measured $v$. putative PS) of PS estimation aids (PSEA) is questionable ${ }^{(18)}$ and the size of some PSEA such as a cup or spoon can be open to interpretation ${ }^{(12)}$. In essence, there is a lack of comprehensive data on consumer understanding of SS guidance $^{(19)}$. In general, consumer estimations of PS, particularly of breakfast cereals ${ }^{(8)}$, tend to deviate from the suggested or recommended $\mathrm{SS}^{(5,20-23)}$. The 5-a-day message is widely recognised guidance for fruit and vegetables $^{(24)}$ yet consumers have expressed their uncertainty as to what equates to a $\mathrm{SS}^{(9)}$.

There is a paucity of both quantitative and qualitative research evaluating the use of appropriate aids to facilitate the estimation of appropriate PS before consumption, despite considerable investigation into their use in dietary assessment after consumption. There is currently a lack of consistent evidence about which, if any, PSEA appear to be most effective in helping consumers to determine appropriate food PS prior to consumption. The main objectives of the present study were to evaluate (in practice) the precision, ease of use and likelihood of future use of a range of PSEA for various foods with diverse characteristics.

Note that, for the purposes of the present study, the term 'PS' refers to the amount of food intended to be consumed whereas 'SS' refers to the amount of food recommended to be consumed. However, it was apparent that the aids selected for the study were inconsistently used to either estimate PS or SS. Therefore, all aids are referred to as 'PSEA' herein.

\section{Experimental methods}

The study was conducted according to the guidelines laid down in the Declaration of Helsinki and all procedures involving human subjects were approved by the University of Ulster, University College Dublin and
Queen's University Belfast Research Ethics Filter Committees. Written informed consent was obtained from all participants before commencing the study protocol.

\section{Participants}

Adults (aged 18-64 years) living on the island of Ireland were recruited to take part in the study via email distribution lists, social media, local advertisements or word of mouth. The study was conducted at three centres including the University of Ulster Coleraine, University College Dublin and Queen's University Belfast. Forty individuals were recruited at each centre over a period of approximately 6 weeks during January and February 2013.

\section{Portion size estimation aids}

A range of PSEA were selected that could be used to aid the estimation of PS of a range of commonly eaten foods of diverse visual and physical properties. These included PSEA for amorphous (i.e. foods without a definite shape such as rice), liquid, solid, cooked and dried foods. The PSEA chosen included: quantities and measures (e.g. SS on food labels); reference objects (e.g. a small matchbox for a SS of cheese); household measures and utensils (e.g. $200 \mathrm{ml}$ disposable cup or coloured portion pots from Rosemary Conley ${ }^{\mathrm{TM}}$ which included a guide detailing the colour of pot that corresponded with certain foods); and indicators on food packets (e.g. SS demarcations on the packaging of a block of cheddar cheese). Only PSEA that were relevant and available to Irish and UK consumers were chosen; others such as the baseball, which originates from the USA, were not included. A full list of the PSEA and their corresponding foods are presented in Table 1.

\section{Study foods}

Sixteen foods in total were selected to pilot the PSEA (Table 1). Foods included were either major contributors to energy intakes on the island of Ireland ${ }^{(25)}$ or were previously identified as challenging in terms of measuring/ quantifying $\mathrm{PS}^{(26)}$. As previously outlined, these foods represented a diversity of shapes and visual characteristics. Pre-defined amounts of the foods were displayed in their original packaging where possible, or otherwise cooked foods were presented in suitable serving dishes (Table 1). Common crockery and utensils were provided for serving out the foods; the sizes of these were kept uniform throughout the study. The relevant PSEA were displayed beside each food with a card detailing the SS recommended by the source of the aid. For example, for mayonnaise, participants could choose to serve out either one level tablespoon using either a typical tablespoon or a measuring spoon with a sliding cover that could adjust from the size of a teaspoon to the size of a tablespoon (household items), $15 \mathrm{~g}$ (using the weighing scales) or an amount the size of the tip of their thumb (reference object). 


\section{Study protocol}

For each food in turn, participants were shown the PSEA that could potentially be used with that food and its respective SS. They were then asked to select the aid they considered to be most appropriate for that food and use it to serve out the indicated SS of that food. Participants were then required to rate each of the PSEA they used in terms of its ease of use (from $1=$ 'not very easy' to $5=$ 'very easy') and the likelihood of using it in future (from $1=$ 'not likely' to $5=$ 'very likely'). Any problems or difficulties encountered while using the PSEA were indicated orally by the participants and noted by the researcher. Participants were then asked to specify foods they thought the PSEA would be most and least useful for, before finally choosing the contexts from a list provided in which they would be most likely to use the PSEA (e.g. eating at work/ breakfast). The weight (in grams) of each food served out was covertly recorded by the researchers.

\section{Analysis}

Statistical analysis was carried out using the statistical software package IBM SPSS Statistics for Windows Version 20.0. Statistical significance was set at $P<0 \cdot 05$. To overcome non-normal distributions, non-parametric testing was used throughout. Descriptive statistics were used to derive median ratings for ease of use and likelihood of using the PSEA again. The precision of the PSEA was assessed based on the range (minimum and maximum values) in grams of the estimated SS for each food (i.e. a wider range of weights was indicative of a less precise aid). The $\chi^{2}$ goodness-of-fit test was used to determine which PSEA participants selected most frequently and to assess the context participants would be most likely to use the PSEA. Open-ended questions were analysed similar to focus group transcripts by using a thematic framework approach, grouping similar problems with the PSEA together to establish themes, and identifying common foods for which the PSEA would be most and least useful.

\section{Results}

\section{Participants}

A total of 120 adults (sixty-one males and fifty-nine females) completed the study protocol, including the demographics questionnaire and the PSEA evaluation. The majority of participants were aged 18-25 years (50\%); of normal weight (self-reported median $\mathrm{BMI}=23.4 \mathrm{~kg} / \mathrm{m}^{2}$ ); single (63\%) postgraduate/undergraduate students (51\%); following no special diet (88\%); and either independently or jointly responsible for preparing and cooking meals (87\%).

\section{Portion size estimation aids selected by participants}

The direct quantification and measuring aids (e.g. using food scales to weigh out the SS on the food label) were the 
least frequently selected PSEA by participants for use during the study protocol, aside from crisps, but no alternative PSEA were available for that particular food. Demarcations on food packaging were the most frequently selected PSEA for foods that need to be sliced (block of cheese, $72 \%$; cake, 69\%), while cutlery was the most frequently selected PSEA for condiments (spread, $72 \%$; mayonnaise, 59\%) and grated cheddar (61\%). For the grains, the majority of participants selected the portion pots for the cooked pasta (74\%) and the breakfast cereals (Rice Krispies, 76\%; Cornflakes, 78\%); however, the disposable cup was the most frequently selected PSEA for the dried rice (44\%; all $P<0 \cdot 001$; Table 2).

\section{Ease of use}

After using the PSEA, participants unanimously rated all PSEA used as being either 'easy to use' (median rating of 4) or 'very easy to use' (median rating of 5). In particular, the quantities and measures and the household measures were given an overall median rating of 5 (i.e. 'very easy to use'; Table 3).

\section{Likelibood of using selected portion size estimation aids in future}

When asked if they would be likely to use the selected PSEA in future, participants indicated that they would be 'likely' or 'very likely' to use the household measures and food packaging again (median ratings overall of 4 and 5, respectively; Table 4). However, while participants were of the opinion that quantities and household measures were easy to use, they were not as likely to use these (median rating overall of 3) particularly not for foods like the grated cheese, lasagne (composite food), crisps or white wine (median ratings of 2 ). In terms of the reference objects, participants indicated that they would be likely to use the food photos again (median rating of 4), but for all other PSEA in that group they said that they 'might' use them in future (median ratings of 3 ).

\section{Precision of portion size estimation aids}

The weighing scales and measuring jug (quantities and measures) were consistently the most precise PSEA for all foods: precision (denoted by the range of weights of the foods served out using these PSEA) ranged from $0 \mathrm{~g}$ for spread to $60 \mathrm{~g}$ for orange juice and was narrower than for all other PSEA (Table 5). Food photos were the least precise, with a range of $336 \mathrm{~g}$ and $391 \mathrm{~g}$ in the amounts estimated by participants for beef curry and lasagne, respectively. Aside from the quantities and measures, the next most precise set of PSEA overall were the household measures; they had a narrower range of estimated weights in comparison with the reference objects and food packaging, with the exceptions of the average glass for the wine (range $190 \mathrm{~g}$ ), the tablespoon for the mayonnaise (range $28 \mathrm{~g}$ ) and the matchbox for the block of cheddar (range $48 \mathrm{~g}$; Table 5).

\section{Context participants would use portion size estimation aids}

The majority of participants indicated they would be most likely to use the PSEA when preparing a meal (94\%), particularly dinner (86\%) in the home (89\%; all $P<0 \cdot 001)$. There were no differences in the number of participants who indicated they would or would not use the PSEA for breakfast $(P=0 \cdot 10)$ and lunch $(P=0 \cdot 715)$. However, the majority of participants indicated they would not use PSEA at any other eating situation, including eating out (93\%) and special occasions (72\%; all $P<0 \cdot 001)$. Males in particular indicated they would not use PSEA at special occasions ( $80 \% ; P=0.032$; Table 6), and there was no difference in the number of underweight $\left(\mathrm{BMI}<18.5 \mathrm{~kg} / \mathrm{m}^{2}\right.$ ) participants who indicated they would or would not use the PSEA at special occasions compared with the other BMI categories, where the majority indicated they would not use the PSEA at special occasions $(P=0.024$; Table 7). Older participants (aged 56-64 years) indicated they would be likely to use the PSEA when eating in the company of friends $(75 \% ; P=0.004)$ and at supper time $(75 \% ; P=0.005)$. There were no other differences according to age, gender (Table 6), BMI or occupation status (Table 7; all $P>0 \cdot 05$ ).

\section{Importance of portion size estimation aids for particular foods}

When participants were asked to list foods for which PSEA would be most useful, the vast majority indicated amorphous grain foods particularly rice, breakfast cereals and pasta. Some participants also noted that PSEA would be useful for potatoes. On the other hand, PSEA were thought to be least useful for fruit and vegetables. The results for other foods were less clear-cut. For example, some participants specified the need for PSEA for specific foods/food groups while others were of the opposite opinion. These foods included: fats and oils (e.g. spreads and mayonnaise); cheese; alcohol; high-fat/sugar snacks (e.g. crisps and cake); meat; chicken; and composite dishes (e.g. curry and lasagne).

\section{Perceived problems encountered when using the portion size estimation aids}

When participants were given the opportunity to note any problems with using the PSEA, some common themes emerged. Overall, using PSEA was considered to be time consuming and inconvenient (particularly the weighing scales), involved more washing up, and was necessary only for those on weight-loss diets. It was also pointed out that using PSEA to estimate PS of hot foods such as cooked pasta before transferring it to a plate could reduce the temperature of the food. For the weighing scales, participants were concerned about getting the exact weight in grams and suggested it may affect the appearance of composite foods like lasagne as it would require adding/ removing smaller amounts until the suggested amount was 
Table 2 Portion size estimation aids selected for each food (\%) by adults (aged 18-64 years) living on the island of Ireland, January-February 2013

\begin{tabular}{|c|c|c|c|c|c|c|c|c|c|c|c|c|c|}
\hline \multirow[b]{2}{*}{ Food group } & \multirow[b]{2}{*}{ Food } & \multirow{2}{*}{$\begin{array}{c}\begin{array}{c}\text { Quantities and } \\
\text { measures }\end{array} \\
\text { Scales/jug }\end{array}$} & \multicolumn{4}{|c|}{ Reference objects } & \multicolumn{5}{|c|}{ Household measures } & \multicolumn{2}{|c|}{ Food packaging } \\
\hline & & & $\begin{array}{l}\text { Food } \\
\text { photos }\end{array}$ & $\begin{array}{c}\text { Hand } \\
\text { physiology }\end{array}$ & $\begin{array}{c}\text { Portion } \\
\text { pack }\end{array}$ & Matchbox & $\begin{array}{l}200 \mathrm{ml} \text { disposable } \\
\text { cup }\end{array}$ & $\begin{array}{l}\text { Portion } \\
\text { pots }\end{array}$ & Cutlery & Glass & $\begin{array}{l}\text { Measuring } \\
\text { spoon }\end{array}$ & $\begin{array}{c}\text { Pack } \\
\text { markings }\end{array}$ & Fractions \\
\hline Dairy & $\begin{array}{l}\text { Cheddar (grated) } \\
\text { Cheddar (block) }\end{array}$ & $\begin{array}{r}14 \\
9\end{array}$ & & & & 19 & & 25 & $61^{* *}$ & & & $72^{* *}$ & \\
\hline \multirow{4}{*}{ Grains } & White rice (uncooked) & 8 & & & & ro & $44^{\star *}$ & 40 & & & & 8 & \\
\hline & Pasta (cooked) & 5 & & & & & 21 & $74^{\star \star}$ & & & & & \\
\hline & Cornflakes & 3 & & & & & 19 & $78^{\star \star \star}$ & & & & & \\
\hline & Rice Krispies & 2 & & & & & 22 & $76^{\star *}$ & & & & & \\
\hline \multirow{4}{*}{$\begin{array}{l}\text { Fruit and } \\
\text { vegetables } \\
\text { Meat dishes }\end{array}$} & Carrots & 10 & & & & & $90^{\star *}$ & & & & & & \\
\hline & Orange juice & 34 & & & & & 29 & & & & & 37 & \\
\hline & Lasagne & 18 & $82^{\star *}$ & & & & & & & & & & \\
\hline & $\begin{array}{l}\text { Chicken pieces } \\
\text { Beef curry }\end{array}$ & $\begin{array}{l}35 \\
18\end{array}$ & $82^{* *}$ & $65^{*}$ & & & & & & & & & \\
\hline \multirow[t]{4}{*}{ High fat/sugar } & Cake & 2 & 28 & & & & & & & & & & $69^{\star \star}$ \\
\hline & Spread & $2^{2}$ & & & 26 & & & & $72^{\star \star}$ & & & & \\
\hline & White wine & 3 & & & & & & 23 & & $73^{\star \star}$ & & & \\
\hline & Mayonnaise & & & 5 & & & & & $59^{\star \star}$ & & 36 & & \\
\hline
\end{tabular}

Significant differences in percentage of participants selecting portion size estimation aids $\left(X^{2}\right.$ goodness-of-fit test): ${ }^{*} P<0.01,{ }^{* *} P<0.001$.

Table 3 Ratings of ease of uset for the portion size estimation aids by adults (aged 18-64 years) living on the island of Ireland, January-February 2013

\begin{tabular}{|c|c|c|c|c|c|c|c|c|c|c|c|c|c|}
\hline \multirow[b]{2}{*}{ Food group } & \multirow[b]{2}{*}{ Food } & \multirow{2}{*}{$\begin{array}{c}\begin{array}{c}\text { Quantities and } \\
\text { measures }\end{array} \\
\text { Scales/jug }\end{array}$} & \multicolumn{4}{|c|}{ Reference objects } & \multicolumn{5}{|c|}{ Household measures } & \multicolumn{2}{|c|}{ Food packaging } \\
\hline & & & $\begin{array}{c}\text { Food } \\
\text { photos }\end{array}$ & $\begin{array}{c}\text { Hand } \\
\text { physiology }\end{array}$ & $\begin{array}{l}\text { Portion } \\
\text { pack }\end{array}$ & Matchbox & $\begin{array}{l}200 \mathrm{ml} \text { disposable } \\
\text { cup }\end{array}$ & $\begin{array}{l}\text { Portion } \\
\text { pots }\end{array}$ & Cutlery & Glass & $\begin{array}{l}\text { Measuring } \\
\text { spoon }\end{array}$ & $\begin{array}{c}\text { Pack } \\
\text { markings }\end{array}$ & Fractions \\
\hline Dairy & $\begin{array}{l}\text { Cheddar (grated) } \\
\text { Cheddar (block) }\end{array}$ & $\begin{array}{l}4 \\
5\end{array}$ & & & & 4 & & 5 & 5 & & & 4 & \\
\hline Grains & $\begin{array}{l}\text { White rice (uncooked) } \\
\text { Pasta (cooked) } \\
\text { Cornflakes } \\
\text { Rice Krispies }\end{array}$ & $\begin{array}{l}5 \\
4 \\
5 \\
5\end{array}$ & & & & 4 & $\begin{array}{l}5 \\
5 \\
4 \\
4\end{array}$ & $\begin{array}{l}5 \\
4 \\
5 \\
5\end{array}$ & & & & 4 & \\
\hline $\begin{array}{l}\text { Fruit and } \\
\text { vegetables }\end{array}$ & $\begin{array}{l}\text { Carrots } \\
\text { Orange juice }\end{array}$ & 4 & & & & & 5 & & & & & 4 & \\
\hline \multirow[t]{2}{*}{ Meat dishes } & $\begin{array}{l}\text { Orange juice } \\
\text { Lasagne }\end{array}$ & $\begin{array}{l}5 \\
4\end{array}$ & 4 & & & & 5 & & & & & 4 & \\
\hline & $\begin{array}{l}\text { Chicken pieces } \\
\text { Beef curry }\end{array}$ & $\begin{array}{l}4 \\
4\end{array}$ & 4 & 4 & & & & & & & & & \\
\hline \multirow[t]{4}{*}{ High fat/sugar } & Cake & 4 & 5 & & & & & & & & & & 5 \\
\hline & $\begin{array}{l}\text { Spread } \\
\text { Crisps }\end{array}$ & $\begin{array}{l}4 \\
5\end{array}$ & & & 4 & & & & 5 & & & & \\
\hline & White wine & 5 & & & & & & 5 & & 5 & & & \\
\hline & $\begin{array}{c}\text { Mayonnaise } \\
\text { Median rating overall }\end{array}$ & 5 & 4 & $\begin{array}{l}5 \\
4\end{array}$ & 4 & 4 & 5 & 5 & $\begin{array}{l}5 \\
5\end{array}$ & 5 & $\begin{array}{l}5 \\
5\end{array}$ & 4 & 5 \\
\hline
\end{tabular}

Values are presented as medians.

†Ease of use ratings range from $1=$ 'not very easy' to $5=$ 'very easy'. 


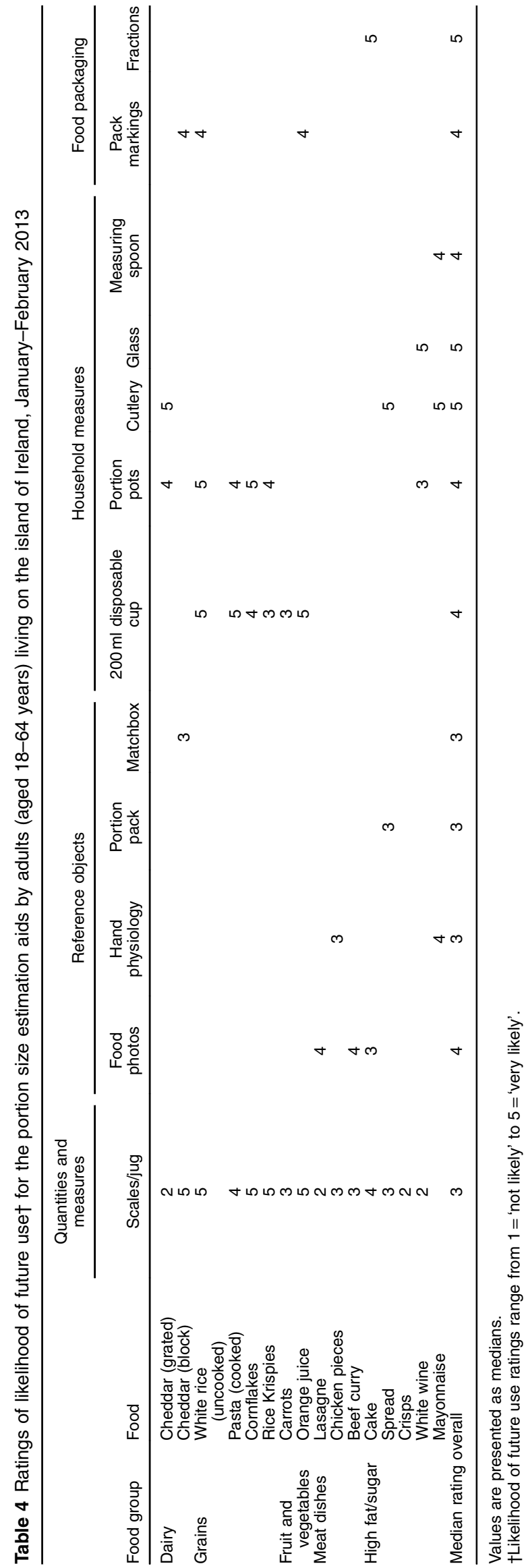

achieved. The main concerns with the portion pots were: they were 'messy' for foods like cooked pasta; difficult to use for liquids without spilling; they are not widely available; and some were unsuitable for left-handed people. Participants who poured cereals into the pots found them 'messy' whereas those who dipped the pot into the cereal box avoided this issue; this was similar for the disposable cup. In addition, some participants thought it was hard to estimate fractions of the cup (e.g. half a cup).

A large proportion of participants had difficulty using the demarcations on the packet of cheese as some chose to try and cut the serving of cheese while it was still in the packet; however, the demarcations did not run to the edge of the packet which made it awkward to use. Others cut through the packet or took the cheese out of the packet and lined it up with the demarcations to overcome this problem. Difficulty was noted in levelling the rice inside the box in order to use the demarcations effectively.

For the visually impaired, there was concern that markings, fractions and other PS or SS estimation aids displayed on food packaging would be too small for them to see. Participants also indicated that it was difficult to judge the size of the visual PSEA (i.e. the objects, hand physiology, fractions and food photos). With regard to food photos, participants also noted that it was difficult to judge the perspective of the photograph, size of the plate and depth of the food.

Finally, participants specified that detailed instructions would be needed for some PSEA (e.g. whether to use a heaped/level tablespoon) and difficulty in differentiating between the sizes of spoons (e.g. tablespoon $v$. dessertspoon) was also noted. Spoons and the graduated spoon were deemed inappropriate for 'sticky' foods like spreads and mayonnaise as there tended to be residue left on the PSEA.

\section{Discussion}

In the present study, the precision, ease of use and likelihood of future use of a range of PSEA were examined in practice. Overall, the household measures (e.g. portion pots and $200 \mathrm{ml}$ disposable cup) were the preferred PSEA. They were deemed easy to use, acceptable for future usage and relatively precise, and would most likely be used when preparing the main meal in the home.

The findings of the present study indicate that although the weighing scales and measuring jug were deemed to be the most precise PSEA, consumers would not be very likely to use them on a regular basis. This is not surprising as consumers generally have little or no concept of weight or volume whether expressed in metric units or the imperial system ${ }^{(5)}$. Furthermore, the weighing scales and measuring jug were seen to be more burdensome. Instead, the household measures appear to be the most userfriendly and relatively precise aids. These findings support 


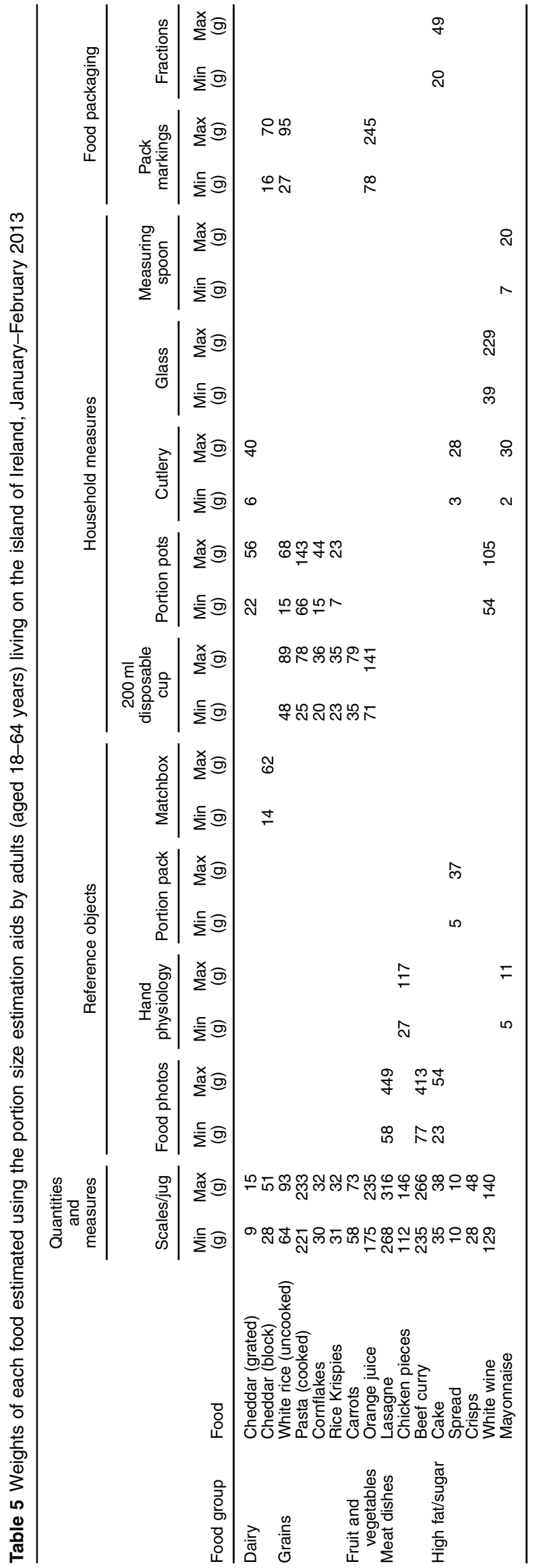

the recent introduction of a standardised cup as a PSEA for the amorphous grains food group in the Healthy Eating Guidelines in the Republic of Ireland ${ }^{(27)}$. Although these methods may not yield the level of accuracy needed for dietary assessment research, they are practical (inexpensive, lightweight, easy to obtain and compact) and have the potential to help consumers control their PS and energy intake on a daily basis ${ }^{(28)}$.

Participants were in favour of using the PSEA for amorphous grains but the majority regarded portion control to be of concern only for those on a special diet. In addition, although they were in agreement that PSEA were generally not necessary for fruit and vegetables, some participants in the current study recognised that the PSEA may facilitate '5-a-day' recommendations. However, there were mixed opinions on the need for PSEA for foods of high energy density. Some participants thought that cutlery such as the spoon were not suitable for 'sticky' foods like mayonnaise and jam that left a residue on the spoon.

To the best of the authors' knowledge, the present study is the first on the island of Ireland to assess the practical application of PSEA pre-consumption. In a previous study, over two-thirds of participants $(n 735)$ in a supermarket survey indicated their preference for the palm of the hand as a PSEA for meat-, poultry- and fish-based products ${ }^{(22)}$. However, after applying hand physiology as a PSEA in the present study, participants merely indicated they 'might' be likely to use it again (scoring a median of 3 out of 5). At present, however, there is no usable alternative PSEA for meat-, poultry- and fish-based products. Therefore, it may be worthwhile promoting that the size of the palm is relative to the individual's needs (i.e. a larger palm is equivalent to a larger PS). Similarly the matchbox, as a reference object for SS of cheese ${ }^{(22)}$, was found to be relatively precise in practice.

Resolution of the problems that arose particularly while using the reference objects and food packaging could improve the precision of these potentially valuable PSEA. Consumers were receptive to the use of such aids but may need additional instructions in order to use them effectively $^{(5)}$, particularly in the case of whether to use a level or heaped spoon ${ }^{(12)}$ and in differentiating between a dessertspoon and a tablespoon. It may also be useful to provide tips on how to save time, for example, by leaving cups in each packet and dipping them into the food to avoid spillages. Instructions on the most appropriate way to use the demarcations and indicators on food packaging may be useful to improve their ease of use and precision, as consumers were relatively receptive to these for use as PSEA also. Indeed, there is further scope to promote the use of PSEA during food preparation as it would avoid the problem of cooked foods, like pasta, cooling down.

Unfortunately, in the present study it was not possible to compare the accuracy of the PSEA (i.e. how close the SS estimated by the participants were to the putative SS that 
Table 6 Likelihood (indicated by yes/no responses) of using the portion size estimation aids at particular eating occasions and situations, by gender and age group, among adults (aged 18-64 years) living on the island of Ireland, January-February 2013

\begin{tabular}{|c|c|c|c|c|c|c|c|c|c|c|c|c|c|c|c|c|c|c|c|c|}
\hline \multirow[b]{3}{*}{ Eating occasion/situation } & \multirow{3}{*}{$\begin{array}{l}\text { Participants' } \\
\text { response }\end{array}$} & & & & \multicolumn{5}{|c|}{ Gender } & \multicolumn{11}{|c|}{ Age group } \\
\hline & & \multicolumn{3}{|c|}{ Total $(n 120)$} & \multicolumn{2}{|c|}{ Male } & \multicolumn{2}{|c|}{ Female } & \multirow[b]{2}{*}{$P$ value } & \multicolumn{2}{|c|}{$\begin{array}{l}18-25 \\
\text { years }\end{array}$} & \multicolumn{2}{|c|}{$\begin{array}{c}26-35 \\
\text { years }\end{array}$} & \multicolumn{2}{|c|}{$\begin{array}{l}36-45 \\
\text { years }\end{array}$} & \multicolumn{2}{|c|}{$\begin{array}{l}46-55 \\
\text { years }\end{array}$} & \multicolumn{2}{|c|}{$\begin{array}{l}56-64 \\
\text { years }\end{array}$} & \multirow[b]{2}{*}{$P$ value } \\
\hline & & $n$ & $\%$ & $P$ value & $n$ & $\%$ & $n$ & $\%$ & & $n$ & $\%$ & $n$ & $\%$ & $n$ & $\%$ & $n$ & $\%$ & $n$ & $\%$ & \\
\hline \multirow[t]{2}{*}{ Eating in } & Yes & 107 & 89 & $<0.001$ & 55 & 90 & 52 & 88 & 0.721 & 52 & 87 & 25 & 89 & 13 & 93 & 10 & 100 & 7 & 88 & 0.768 \\
\hline & No & 13 & 11 & & 6 & 10 & 7 & 12 & & 8 & 13 & 3 & 11 & 1 & 7 & 0 & 0 & 1 & 13 & \\
\hline \multirow[t]{2}{*}{ Eating out } & Yes & 9 & 8 & $<0.001$ & 4 & 7 & 5 & 8 & 0.690 & 3 & 5 & 3 & 11 & 0 & 0 & 1 & 10 & 2 & 25 & 0.222 \\
\hline & No & 111 & 93 & & 57 & 93 & 54 & 92 & & 57 & 95 & 25 & 89 & 14 & 100 & 9 & 90 & 6 & 75 & \\
\hline \multirow[t]{2}{*}{ At work } & Yes & 41 & 34 & 0.001 & 16 & 26 & 25 & 42 & 0.062 & 16 & 27 & 14 & 50 & 3 & 21 & 3 & 30 & 5 & 63 & 0.073 \\
\hline & No & 79 & 66 & & 45 & 74 & 34 & 58 & & 44 & 73 & 14 & 50 & 11 & 79 & 7 & 70 & 3 & 38 & \\
\hline \multirow[t]{2}{*}{ Eating with friends } & Yes & 32 & 27 & $<0.001$ & 15 & 25 & 17 & 29 & 0.601 & 15 & 25 & 9 & 32 & 0 & 0 & 2 & 20 & 6 & 75 & 0.004 \\
\hline & No & 88 & 73 & & 46 & 75 & 42 & 71 & & 45 & 75 & 19 & 68 & 14 & 100 & 8 & 80 & 2 & 25 & \\
\hline \multirow[t]{2}{*}{ In stressful situations } & Yes & 14 & 12 & $<0.001$ & 7 & 11 & 7 & 12 & 0.947 & 4 & 7 & 5 & 18 & 1 & 7 & 1 & 10 & 3 & 38 & 0.092 \\
\hline & No & 106 & 88 & & 54 & 89 & 52 & 88 & & 56 & 93 & 23 & 82 & 13 & 93 & 9 & 90 & 5 & 63 & \\
\hline Lack of time & Yes & 24 & 20 & $<0.001$ & 14 & 23 & 10 & 17 & 0.411 & 11 & 18 & 6 & 21 & 3 & 21 & 2 & 20 & 2 & 25 & 0.991 \\
\hline & No & 96 & 80 & & 47 & 77 & 49 & 83 & & 49 & 82 & 22 & 79 & 11 & 79 & 8 & 80 & 6 & 75 & \\
\hline Special occasions & Yes & 34 & 28 & $<0.001$ & 12 & 20 & 22 & 37 & 0.032 & 17 & 28 & 8 & 29 & 3 & 21 & 2 & 20 & 4 & 50 & 0.641 \\
\hline & No & 86 & 72 & & 49 & 80 & 37 & 63 & & 43 & 72 & 20 & 71 & 11 & 79 & 8 & 80 & 4 & 50 & \\
\hline Eating late or after a night out & Yes & 16 & 13 & $<0.001$ & 8 & 13 & 8 & 14 & 0.943 & 6 & 10 & 3 & 11 & 1 & 7 & 3 & 30 & 3 & 38 & 0.105 \\
\hline & No & 104 & 87 & & 53 & 87 & 51 & 86 & & 54 & 90 & 25 & 89 & 13 & 93 & 7 & 70 & 5 & 63 & \\
\hline Watching television & Yes & 31 & 26 & $<0.001$ & 16 & 26 & 15 & 25 & 0.929 & 16 & 27 & 8 & 29 & 2 & 14 & 2 & 20 & 3 & 38 & 0.763 \\
\hline & No & 89 & 74 & & 45 & 74 & 44 & 75 & & 44 & 73 & 20 & 71 & 12 & 86 & 8 & 80 & 5 & 63 & \\
\hline Preparing a meal & Yes & 113 & 94 & $<0.001$ & 56 & 92 & 57 & 97 & 0.261 & 56 & 93 & 27 & 96 & 14 & 100 & 9 & 90 & 7 & 88 & 0.705 \\
\hline & No & 7 & 6 & & 5 & 8 & 2 & 3 & & 4 & 7 & 1 & 4 & 0 & 0 & 1 & 10 & 1 & 13 & \\
\hline Shopping for food & Yes & 36 & 30 & $<0.001$ & 16 & 26 & 20 & 34 & 0.359 & 13 & 22 & 12 & 43 & 7 & 50 & 3 & 30 & 1 & 13 & 0.091 \\
\hline & No & 84 & 70 & & 45 & 74 & 39 & 66 & & 47 & 78 & 16 & 57 & 7 & 50 & 7 & 70 & 7 & 88 & \\
\hline Breakfast & Yes & 69 & 58 & 0.100 & 33 & 54 & 36 & 61 & 0.443 & 33 & 55 & 17 & 61 & 7 & 50 & 5 & 50 & 7 & 88 & 0.438 \\
\hline & No & 51 & 43 & & 28 & 46 & 23 & 39 & & 27 & 45 & 11 & 39 & 7 & 50 & 5 & 50 & 1 & 13 & \\
\hline Lunch & Yes & 62 & 52 & 0.715 & 27 & 44 & 35 & 59 & 0.099 & 30 & 50 & 16 & 57 & 5 & 36 & 5 & 50 & 6 & 75 & 0.465 \\
\hline & No & 58 & 48 & & 34 & 56 & 24 & 41 & & 30 & 50 & 12 & 43 & 9 & 64 & 5 & 50 & 2 & 25 & \\
\hline Dinner & Yes & 103 & 86 & $<0.001$ & 50 & 82 & 53 & 90 & 0.217 & 48 & 80 & 26 & 93 & 13 & 93 & 9 & 90 & 7 & 88 & 0.471 \\
\hline & No & 17 & 14 & & 11 & 18 & 6 & 10 & & 12 & 20 & 2 & 7 & 1 & 7 & 1 & 10 & 1 & 13 & \\
\hline Supper & Yes & 39 & 33 & $<0.001$ & 21 & 34 & 18 & 31 & 0.647 & 12 & 20 & 14 & 50 & 4 & 29 & 3 & 30 & 6 & 75 & 0.005 \\
\hline & No & 81 & 68 & & 40 & 66 & 41 & 69 & & 48 & 80 & 14 & 50 & 10 & 71 & 7 & 70 & 2 & 25 & \\
\hline Snacks & Yes & 39 & 33 & $<0.001$ & 19 & 31 & 20 & 34 & 0.748 & 14 & 23 & 15 & 54 & 4 & 29 & 3 & 30 & 3 & 38 & 0.085 \\
\hline & No & 81 & 68 & & 42 & 69 & 39 & 66 & & 46 & 77 & 13 & 46 & 10 & 71 & 7 & 70 & 5 & 63 & \\
\hline Drinks & Yes & 35 & 29 & $<0.001$ & 17 & 28 & 18 & 31 & 0.750 & 13 & 22 & 9 & 32 & 6 & 43 & 4 & 40 & 3 & 38 & 0.425 \\
\hline & No & 85 & 71 & & 44 & 72 & 41 & 69 & & 47 & 78 & 19 & 68 & 8 & 57 & 6 & 60 & 5 & 63 & \\
\hline Other & Yes & 6 & 5 & $<0.001$ & 3 & 5 & 3 & 5 & 0.967 & 1 & 2 & 2 & 7 & 0 & 0 & 2 & 20 & 1 & 13 & 0.088 \\
\hline & No & 114 & 95 & & 58 & 95 & 56 & 95 & & 59 & 98 & 26 & 93 & 14 & 100 & 8 & 80 & 7 & 88 & \\
\hline
\end{tabular}

Significant $P$ values $\left(X^{2}\right.$ goodness-of-fit test) are indicated in bold font. 


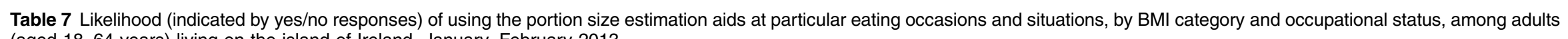
(aged 18-64 years) living on the island of Ireland, January-February 2013

\begin{tabular}{|c|c|c|c|c|c|c|c|c|c|c|c|c|c|c|c|c|c|c|c|c|c|c|c|c|c|}
\hline \multirow{3}{*}{$\begin{array}{l}\text { Eating occasion/ } \\
\text { situation }\end{array}$} & \multirow{3}{*}{$\begin{array}{l}\text { Participants' } \\
\text { response }\end{array}$} & \multicolumn{9}{|c|}{ BMI category $†$} & \multicolumn{15}{|c|}{ Current occupational status } \\
\hline & & \multicolumn{2}{|c|}{ Underweight } & \multicolumn{2}{|c|}{$\begin{array}{l}\text { Normal } \\
\text { weight }\end{array}$} & \multicolumn{2}{|c|}{ Overweight } & \multicolumn{2}{|c|}{ Obese } & \multirow[b]{2}{*}{$P$ value } & \multicolumn{2}{|c|}{$\begin{array}{l}\text { Employed } \\
\text { full-time }\end{array}$} & \multicolumn{2}{|c|}{$\begin{array}{l}\text { Employed } \\
\text { part-time }\end{array}$} & \multicolumn{2}{|c|}{$\begin{array}{c}\text { Full-time } \\
\text { home } \\
\text { maker }\end{array}$} & \multicolumn{2}{|c|}{ Unemployed } & \multicolumn{2}{|c|}{ Student } & \multicolumn{2}{|c|}{$\begin{array}{c}\text { Never } \\
\text { worked }\end{array}$} & \multicolumn{2}{|c|}{ Retired } & \multirow[b]{2}{*}{$P$ value } \\
\hline & & $n$ & $\%$ & $n$ & $\%$ & $n$ & $\%$ & $n$ & $\%$ & & $n$ & $\%$ & $n$ & $\%$ & $n$ & $\%$ & $n$ & $\%$ & $n$ & $\%$ & $n$ & $\%$ & $n$ & $\%$ & \\
\hline Eating in & Yes & 5 & 83 & 63 & 88 & 23 & 100 & 11 & 85 & 0.312 & 43 & 88 & 6 & 100 & 2 & 100 & 2 & 100 & 54 & 89 & 0 & 0 & 0 & 0 & 0.854 \\
\hline & No & 1 & 17 & 9 & 13 & 0 & 0 & 2 & 15 & & 6 & 12 & 0 & 0 & 0 & 0 & 0 & 0 & 7 & 11 & 0 & 0 & 0 & 0 & \\
\hline Eating out & Yes & 1 & 17 & 2 & 3 & 3 & 13 & 2 & 15 & 0.138 & 3 & 6 & 2 & 33 & 0 & 0 & 0 & 0 & 4 & 7 & 0 & 0 & 0 & 0 & $0 \cdot 177$ \\
\hline & No & 5 & 83 & 70 & 97 & 20 & 87 & 11 & 85 & & 46 & 94 & 4 & 67 & 2 & 100 & 2 & 100 & 57 & 93 & 0 & 0 & 0 & 0 & \\
\hline At work & Yes & 2 & 33 & 22 & 31 & 9 & 39 & 6 & 46 & 0.682 & 21 & 43 & 3 & 50 & 0 & 0 & 0 & 0 & 17 & 28 & 0 & 0 & 0 & 0 & 0.243 \\
\hline & No & 4 & 67 & 50 & 69 & 14 & 61 & 7 & 54 & & 28 & 57 & 3 & 50 & 2 & 100 & 2 & 100 & 44 & 72 & 0 & 0 & 0 & 0 & \\
\hline Eating with friends & Yes & 2 & 33 & 17 & 24 & 9 & 39 & 4 & 31 & 0.526 & 14 & 29 & 2 & 33 & 1 & 50 & 0 & 0 & 15 & 25 & 0 & 0 & 0 & 0 & 0.801 \\
\hline & No & 4 & 67 & 55 & 76 & 14 & 61 & 9 & 69 & & 35 & 71 & 4 & 67 & 1 & 50 & 2 & 100 & 46 & 75 & 0 & 0 & 0 & 0 & \\
\hline In stressful situations & Yes & 1 & 17 & 7 & 10 & 4 & 17 & 1 & 8 & 0.715 & 7 & 14 & 1 & 17 & 0 & 0 & 1 & 50 & 5 & 8 & 0 & 0 & 0 & 0 & 0.367 \\
\hline & No & 5 & 83 & 65 & 90 & 19 & 83 & 12 & 92 & & 42 & 86 & 5 & 83 & 2 & 100 & 1 & 50 & 56 & 92 & 0 & 0 & 0 & 0 & \\
\hline Lack of time & Yes & 0 & 0 & 17 & 24 & 5 & 22 & 1 & 8 & 0.343 & 11 & 22 & 2 & 33 & 1 & 50 & 0 & 0 & 10 & 16 & 0 & 0 & 0 & 0 & 0.563 \\
\hline & No & 6 & 100 & 55 & 76 & 18 & 78 & 12 & 92 & & 38 & 78 & 4 & 67 & 1 & 50 & 2 & 100 & 51 & 84 & 0 & 0 & 0 & 0 & \\
\hline Special occasions & Yes & 3 & 50 & 27 & 38 & 2 & 9 & 2 & 15 & 0.024 & 14 & 29 & 4 & 67 & 0 & 0 & 0 & 0 & 16 & 26 & 0 & 0 & 0 & 0 & 0.195 \\
\hline & No & 3 & 50 & 45 & 63 & 21 & 91 & 11 & 85 & & 35 & 71 & 2 & 33 & 2 & 100 & 2 & 100 & 45 & 74 & 0 & 0 & 0 & 0 & \\
\hline Eating late or after & Yes & 2 & 33 & 9 & 13 & 1 & 4 & 2 & 15 & 0.269 & 7 & 14 & 3 & 50 & 0 & 0 & 0 & 0 & 6 & 10 & 0 & 0 & 0 & 0 & 0.082 \\
\hline a night out & No & 4 & 67 & 63 & 88 & 22 & 96 & 11 & 85 & & 42 & 86 & 3 & 50 & 2 & 100 & 2 & 100 & 55 & 90 & 0 & 0 & 0 & 0 & \\
\hline Watching television & Yes & 2 & 33 & 17 & 24 & 7 & 30 & 3 & 23 & 0.881 & 12 & 24 & 3 & 50 & 1 & 50 & 1 & 50 & 14 & 23 & 0 & 0 & 0 & 0 & 0.500 \\
\hline & No & 4 & 67 & 55 & 76 & 16 & 70 & 10 & 77 & & 37 & 76 & 3 & 50 & 1 & 50 & 1 & 50 & 47 & 77 & 0 & 0 & 0 & 0 & \\
\hline Preparing a meal & Yes & 6 & 100 & 65 & 90 & 23 & 100 & 13 & 100 & 0.226 & 46 & 94 & 6 & 100 & 2 & 100 & 2 & 100 & 57 & 93 & 0 & 0 & 0 & 0 & 0.953 \\
\hline & No & 0 & 0 & 7 & 10 & 0 & 0 & 0 & 0 & & 3 & 6 & 0 & 0 & 0 & 0 & 0 & 0 & 4 & 7 & 0 & 0 & 0 & 0 & \\
\hline Shopping for food & Yes & 1 & 17 & 20 & 28 & 9 & 39 & 3 & 23 & 0.601 & 18 & 37 & 1 & 17 & 0 & 0 & 2 & 100 & 15 & 25 & 0 & 0 & 0 & 0 & 0.094 \\
\hline & No & 5 & 83 & 52 & 72 & 14 & 61 & 10 & 77 & & 31 & 63 & 5 & 83 & 2 & 100 & 0 & 0 & 46 & 75 & 0 & 0 & 0 & 0 & \\
\hline Breakfast & Yes & 4 & 67 & 40 & 56 & 14 & 61 & 8 & 62 & 0.918 & 29 & 59 & 6 & 100 & 0 & 0 & 1 & 50 & 33 & 54 & 0 & 0 & 0 & 0 & 0.110 \\
\hline & No & 2 & 33 & 32 & 44 & 9 & 39 & 5 & 38 & & 20 & 41 & 0 & 0 & 2 & 100 & 1 & 50 & 28 & 46 & 0 & 0 & 0 & 0 & \\
\hline Lunch & Yes & 4 & 67 & 31 & 43 & 14 & 61 & 9 & 69 & 0.169 & 26 & 53 & 5 & 83 & 1 & 50 & 1 & 50 & 29 & 48 & 0 & 0 & 0 & 0 & 0.580 \\
\hline & No & 2 & 33 & 41 & 57 & 9 & 39 & 4 & 31 & & 23 & 47 & 1 & 17 & 1 & 50 & 1 & 50 & 32 & 52 & 0 & 0 & 0 & 0 & \\
\hline Dinner & Yes & 6 & 100 & 59 & 82 & 20 & 87 & 12 & 92 & 0.530 & 44 & 90 & 5 & 83 & 2 & 100 & 2 & 100 & 50 & 82 & 0 & 0 & 0 & 0 & 0.722 \\
\hline & No & 0 & 0 & 13 & 18 & 3 & 13 & 1 & 8 & & 5 & 10 & 1 & 17 & 0 & 0 & 0 & 0 & 11 & 18 & 0 & 0 & 0 & 0 & \\
\hline Supper & Yes & 3 & 50 & 23 & 32 & 8 & 35 & 5 & 38 & 0.817 & 20 & 41 & 2 & 33 & 0 & 0 & 1 & 50 & 16 & 26 & 0 & 0 & 0 & 0 & 0.422 \\
\hline & No & 3 & 50 & 49 & 68 & 15 & 65 & 8 & 62 & & 29 & 59 & 4 & 67 & 2 & 100 & 1 & 50 & 45 & 74 & 0 & 0 & 0 & 0 & \\
\hline Snacks & Yes & 3 & 50 & 21 & 29 & 8 & 35 & 5 & 38 & 0.690 & 19 & 39 & 2 & 33 & 2 & 100 & 0 & 0 & 16 & 26 & 0 & 0 & 0 & 0 & 0.131 \\
\hline & No & 3 & 50 & 51 & 71 & 15 & 65 & 8 & 62 & & 30 & 61 & 4 & 67 & 0 & 0 & 2 & 100 & 45 & 74 & 0 & 0 & 0 & 0 & \\
\hline Drinks & Yes & 2 & 33 & 25 & 35 & 5 & 22 & 2 & 15 & 0.411 & 15 & 31 & 2 & 33 & 0 & 0 & 0 & 0 & 18 & 30 & 0 & 0 & 0 & 0 & 0.782 \\
\hline & No & 4 & 67 & 47 & 65 & 18 & 78 & 11 & 85 & & 34 & 69 & 4 & 67 & 2 & 100 & 2 & 100 & 43 & 70 & 0 & 0 & 0 & 0 & \\
\hline Other & Yes & 0 & 0 & 4 & 6 & 2 & 9 & 0 & 0 & 0.657 & 5 & 10 & 0 & 0 & 0 & 0 & 0 & 0 & 1 & 2 & 0 & 0 & 0 & 0 & 0.312 \\
\hline & No & 6 & 100 & 68 & 94 & 21 & 91 & 13 & 100 & & 44 & 90 & 6 & 100 & 2 & 100 & 2 & 100 & 60 & 98 & 0 & 0 & 0 & 0 & \\
\hline
\end{tabular}

Significant $P$ values $\left(x^{2}\right.$ goodness-of-fit test) are indicated in bold font.

†Underweight, BMI < 18.5 kg/m²; normal weight, BMI = 18.5-24.9 kg/ $/ \mathrm{m}^{2}$; overweight, $\mathrm{BMI}=25.0-29.9 \mathrm{~kg} / \mathrm{m}^{2} ;$ obese, $\mathrm{BMI} \geq 30.0 \mathrm{~kg} / \mathrm{m}^{2}$. 
they aimed to serve out with each PSEA). This was because, for many of the PSEA, there was no indication as to the basis of its SS or the weight of the SS in grams that it aimed to represent. Indeed, as the putative SS for some PSEA were either unknown or inconsistent due to different aims (e.g. weight loss or weight maintenance), it was not appropriate to compare their median estimated weights as a means of assessing their accuracy. However, the ranges of the estimated weights served out of each food were compared to examine the precision of the PSEA.

The relative imprecision of SS estimated with the aid of reference objects, particularly food photographs, is an issue that needs to be addressed. A previous report recommended a combination of PSEA that included visual images ${ }^{(9)}$. However, in the present study, a wide range of SS were estimated with food photographs which suggests they may not be an accurate guide to their intended SS. Participants highlighted the fact that it was difficult to judge the size of the plate, depth of the food and perspective of the food photograph. In addition, its been found that consumers can be sceptical of food photographs when displayed on food packaging with the belief that they are for marketing purposes only ${ }^{(5)}$. In contrast, food photographs were found to be relatively accurate PSEA for use with children ${ }^{(28-30)}$. Nevertheless, there are no validated alternative PSEA for composite foods. Therefore, further development is needed to establish effective PSEA for home-cooked and amorphous composite dishes ${ }^{(9)}$. Three-dimensional food models have previously been effective in the classroom setting ${ }^{(31)}$, yet other aids such as adjustable wedges and rulers have resulted in some error ${ }^{(32)}$. Alternatively, perhaps the application of demarcations and fractions could be extended to packaged composite foods that require slicing such as pies and lasagne. In addition, a recent Canadian study advised caution with the use of reference objects as an evaluation of a range of household- and sports-related objects revealed that they did not always reflect the true weight or volume of food as intended ${ }^{(18)}$. This highlights the need to have a sound and consistent basis for the putative weights and volumes of PSEA, and to provide clear indication as to whether they are aimed at optimising health or aiding weight loss in order to resonate with consumers and portray realistic SS.

\section{Conclusion}

In terms of precision, ease of use and likelihood of future use, household measures should be promoted to consumers as effective aids for the estimation of appropriate PS of amorphous grains such as rice. Food packaging (i.e. demarcations and fractions) may be an effective aid for foods that require slicing such as cheese; however, they should be accompanied by clear instructions in order to improve precision. Further research is needed to establish more precise PSEA for composite foods. In conclusion, the provision of 'fit-for-purpose' PSEA and guidance is vital to empower consumers with the ability and motivation to select more appropriate PS.

\section{Acknowledgements}

Acknowledgements: The authors would like to acknowledge Miss Ciara McGolderick and Miss Marie Goulding for helping with data collection. Financial support: $\mathrm{PhD}$ sponsorship (G.P.F.) was obtained from the Department for Employment and Learning (DEL), Northern Ireland. This material is based on works supported by safefood, the Food Safety Promotion Board (grant number 07-2010). safefood had no role in the design, analysis or writing of this article. Conflict of interest: None. Authorship: G.P.F., M.B.E.L., M.A.K., T.A.M.C., J.M.W.W. and L.K.P. formulated the research questions and designed the study protocol. G.P.F. and L.K.P. carried out the study and analysed the data. G.P.F. wrote the manuscript. M.B.E.L., M.A.K., T.A.M.C., M.S., M.D., S.O.B. and E.R.G provided guidance on the analysis and write-up, and comment on drafts of the manuscript. Ethics of buman subject participation: This study was conducted according to the guidelines laid down in the Declaration of Helsinki and all procedures involving human subjects were approved by the University of Ulster, University College Dublin and Queen's University Belfast Research Ethics Filter Committees.

\section{References}

1. Wansink B \& van Ittersum K (2007) Portion size me: downsizing our consumption norms. J Am Diet Assoc 107, 1103-1106.

2. Nielsen SJ \& Popkin BM (2003) Patterns and trends in food portion sizes, 1977-1998. JAMA 289, 450-453.

3. Anderson AS, Freeman J, Stead M et al. (2005) Consumer Views on Portion Size Guidance to Assist Adult Dietary Choices. Canada: Canadian Diabetes Association.

4. Brown KA, Timotijevic L, Barnett J et al. (2011) A review of consumer awareness, understanding and use of food-based dietary guidelines. Br J Nutr 106, 15-26.

5. Institute of Grocery Distribution (2009) Portion Size: Understanding the Consumer Perspective. Watford: IGD.

6. Wood F, Robling M, Prout H et al. (2010) A question of balance: a qualitative study of mother's interpretations of dietary recommendations. Ann Fam Med 8, 51-57.

7. Institute of Grocery Distribution (2009) Portion Size Communication in Therapeutic Practice. Watford: IGD.

8. British Market Research Bureau Qualitative (2010) Citizens' Forums on Food: Front-of-Pack Nutrition Labelling. London: Food Standards Agency.

9. Anderson AS, Barton K, Craigie A et al. (2008) Exploration of Adult Food Portion Size Tools. Edinburgh: NHS Health Scotland.

10. Food Standards Agency (2007) The Eatwell Plate. http:// www.food.gov.uk/multimedia/pdfs/theeatwellplate.pdf (accessed March 2013).

11. The British Dietetic Association (2007) Dietitians Hail Return of Balanced Diet Plate. Birmingham: BDA. 
12. Wrieden WL \& Momen NC (2009) Workshop 3: Novel approaches for estimating portion sizes. Eur J Clin Nutr $\mathbf{6 3}$, Suppl. 1, S80-S81.

13. Young LR \& Nestle M (1998) Variation in perceptions of a 'medium' food portion: implications for dietary guidance. J Am Diet Assoc 98, 458-459.

14. Food Safety Authority of Ireland (2012) Healthy Eating and Active Living for Adults, Teenagers and Children over 5 years - A Food Guide for Health Professionals and Catering Services. Dublin: FSAI.

15. Hogbin M \& Hess M (1999) Public confusion over food portions and servings. J Am Diet Assoc 99, 1209-1211.

16. Ovaskainen M, Paturi M, Reinivuo H et al. (2008) Accuracy in the estimation of food servings against the portions in food photographs. Eur J Clin Nutr 62, 674-681.

17. Robson PJ \& Livingstone MB (2000) An evaluation of food photographs as a tool for quantifying food and nutrient intakes. Public Health Nutr 3, 183-192.

18. Ball GDC \& Friedman A (2010) Dice, golf balls, and CDs: assumptions about portion size measurement aids. Can J Diet Pract Res 71, 146-149.

19. Institute of Grocery Distribution (2008) Portion Size: A Review of Existing Approaches. Watford: IGD.

20. Britten P, Haven J \& Davis C (2006) Consumer research for development of educational messages for the MyPyramid food guidance system. J Nutr Educ Behav 38, 6 Suppl., S108-S123.

21. Brogden N \& Almiron-Roig E (2011) Estimated portion sizes of snacks and beverages differ from reference amounts and are affected by appetite status in non-obese men. Public Health Nutr 14, 1743-1751.

22. Flynn MAT, O'Brien CM, Faulkner G et al. (2012) Revision of food-based dietary guidelines for Ireland, phase 1: evaluation of Ireland's food guide. Public Health Nutr $\mathbf{1 5}$, 518-526.

23. Schwartz J \& Byrd-Bredbenner C (2006) Portion distortion: typical portion sizes selected by young adults. $J$ Am Diet Assoc 106, 1412-1418.

24. National Health Service (2003) 5 A DAY portion sizes. http://www.nhs.uk/Livewell/5ADAY/Pages/Portionsizes.aspx (accessed March 2013).

25. Irish Universities Nutrition Alliance (2011) National Adult Nutritional Survey - Summary Report on Food and Nutrient Intakes, Physical Measurements, Physical Activity Patterns and Food Choice Motives. Ireland: IUNA.

26. Faulkner GP, Pourshahidi LK, Wallace JMW et al. (2012) Serving size guidance for consumers: is it effective? Proc Nutr Soc 71, 610-621.

27. Food Safety Authority of Ireland (2011) Scientific Recommendations for Healthy Eating in Ireland. Dublin: FSAI.

28. Thoradeniya T, de Silva A, Arambepola C et al. (2012) Portion size estimation aids for Asian foods. J Hum Nutr Diet 25, 497-504.

29. Lillegaard ITL, Overby NC \& Andersen LF (2005) Can children and adolescents use photographs of food to estimate portion sizes? Eur J Clin Nutr 59, 611-617.

30. Foster E, Matthews JNS, Lloyd J et al. (2008) Children's estimates of food portion size: the development and evaluation of three portion size assessment tools for use with children. Br J Nutr 99, 175-184.

31. Brown L \& Oler C (2000) A food display assignment and handling food models improves accuracy of college students' estimates of food portions. J Am Diet Assoc 100, 1063-1065.

32. Godwin S, Chambers E, Cleveland L et al. (2006) A new portion size estimation aid for wedge-shaped foods. $J \mathrm{Am}$ Diet Assoc 106, 1246-1250. 